\title{
Knowledge, Attitudes, and Practice of Housewives As Members of the Environmental Community Against Household Food Waste Management
}

\author{
Kartini Aryani Zahara ${ }^{1}$, Hasibuan Hayati Sari ${ }^{{ }^{*}}$, and Tumuyu Sri Setiawati ${ }^{1}$ \\ ${ }^{1}$ School of Environmental Science, Universitas Indonesia, Special Capital Region of Jakarta, \\ Indonesia
}

\begin{abstract}
The amount of food waste is a serious problem. That will happen to an imbalance in the food supply chain. The role of housewives is very important for food waste management. Leftover food that became important waste managed creatively and innovatively. Incorrect information by housewives will result in food waste that is still suitable for consumption in the garbage. This research analyzes the knowledge, attitudes, and practice of housewives who are members of the environmental community towards food waste produced in the household by the qualitative method. Data collection through questionnaires, participant observation, and in-depth interviews and comparing the results of the three analyzes in a balanced manner. The sample consisted of 25 housewives. The results of the study state that knowledge, attitudes and practice affect the results of each participant's food waste.
\end{abstract}

\section{Introduction}

At this time, the focus of the world is trying to reduce food loss and food waste in developing and developed countries. This is because it generates food waste along the supply chain from production, post-harvest, processing, and distribution until human consumption [1]. It is estimated that one-third of the food produced for human consumption, equivalent to 1.3 billion tonnes each year becomes food waste [2]. Based on the Food Sustainability Index (2019), Indonesia resulted in a $61.40 \%$ loss of food and food waste from the sum of waste [3]. The consumer approach is a way to reduce food waste. This is because half of the world's food waste is caused by consumption habits and activities [4]. Food waste originating from households is influenced by the role of housewives. Women lean to produce more food waste than men. This is because women are responsible for shopping and managing groceries for their families [5].

The factors that influence the increase in food waste are the availability of cheap food but low qualities packaging, poor purchasing planning, perishable food [6]. Grunert et al. (2010) stated that this household waste could be caused by consumer ignorance of product packaging label information based on a survey of 921 respondents in the UK. Only $27 \%$

*) Corresponding author: hayati.hasibuan@ui.ac.id 
understand it [7]. Waste of food in households is a sustainability challenge that raises environmental and social problems. It is estimated that 1 household disposes of $1.9 \mathrm{~kg}$ of food waste per week or about $40 \mathrm{~kg}$ per year [8]. This problem has led to the emergence of an environmental movement caused by a widespread environmental crisis accompanied by growing public awareness of the importance of protecting the environment [9]. Large amounts of food waste can occur in areas that cannot manage and reduce food waste.

The more prosperous the community is smart it is in managing and reducing food waste. South Jakarta ranks second as the largest waste producer in DKI Jakarta, a percentage of waste generated at 1,600 tons per day, and $44 \%$ of the total waste is food waste [10]. According to UNEP (2014), Efforts in developing and implementing programs to prevent and reduce household and consumer food and beverage waste require 2 (two) main keys are socialization and understanding of the role of labels and food storage methods [11]. The private sector is seen capable of contributing to various urban waste management activities, including collection, transportation, processing, separate collection, recycling, composting, and waste disposal. This condition encourages the South Jakarta provincial government to make several programs, one of which is a waste bank. Housewives who are members of a waste bank are considered capable of managing food waste, but a deeper analysis is needed for this.

Thus the aim of this paper was to analyze knowledge, attitudes, and behavior of housewives as members of the environmental community towards household food waste.

\section{Methods}

\subsection{Research approach}

This research uses a qualitative method approach. Qualitative methods are used to collect data on knowledge, attitude, and behaviour of women (housewives) as members of the environmental community against household food waste. Quantitative methods were conducted with surveys and data collection techniques with questionnaires, participant observation, and in-depth interviews and comparing the results of the three analyzes in a balanced manner. The location of the research was conducted in South Jakarta. The study was conducted for two months, from September 2020 until October 2020.

\subsection{Sampling and data collection}

The population in this study were members of the Berseri Waste Bank at Pondok Labu Village, South Jakarta. The population members of the Berseri Waste Bank is 68 people as active members. However, participants were selected based on the hamlet category with the highest to the lowest rank in producing recycled waste based on observations and interviews with the founder of the Berseri Waste Bank. The order is as follows, neighbourhood 1 is the highest rank, neighbourhood 3 is the middle rank, and it is the lowest rank neighbourhood 2 . The sampling technique used is a non-probability saturation technique. Thus a sample of 25 households was obtained from all members of the Berseri Waste Bank in neighbourhoods 1, 2, 3 .

*) Corresponding author: hayati.hasibuan@ui.ac.id 


\section{Results and implication}

Food is a basic need and right of every living thing. This household food waste consists of food waste from packaged products and non-packaged products. Packaged products are food products are wrapped in food-grade materials so that the product is more durable, apart from that as marketing in driving sales, for example, instant noodles, instant coffee, frozen food. In comparison, non-packaged products are unpackaged products or fresh products such as unprocessed vegetables, fruit, chicken, or fish.

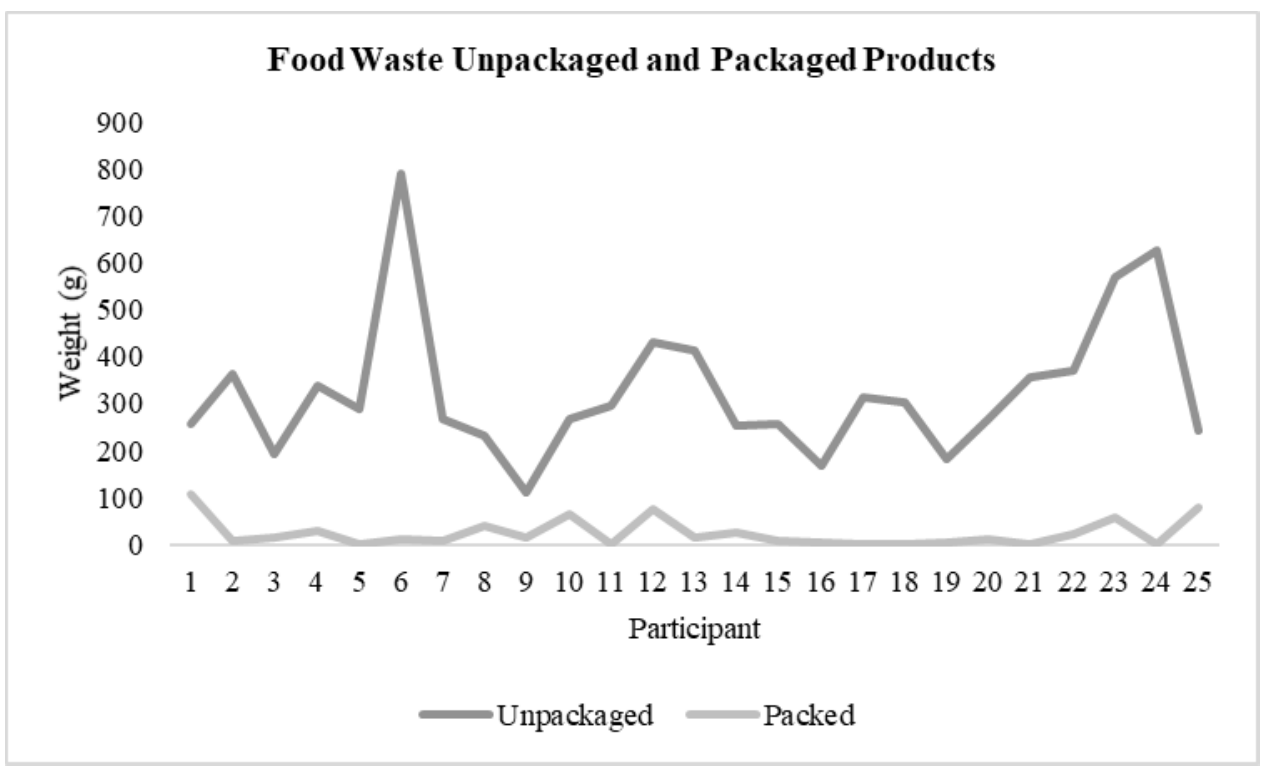

Fig. 1. Unpackaged and Packaged Product Food Waste.

Sources: Author's Analysis, 2020

Based on the results of research in graph 1, the average participant contributed $327 \mathrm{~g} \mathrm{a}$ day per person of non-packaged food waste while $24 \mathrm{~g}$ a day per person of packaged food waste. There are several factors that influence the food waste generated among households. According to Stefen et al., that food waste among consumers is determined from the behaviour and habits of consumers in controlling every routine in providing daily food needs [12]. In the FGD process and the observations made, it can be seen that knowledge, attitudes and practice influence the participants' decisions in determining what types of food are appropriate for them and their families to consume and which foods should be discarded.

I have taught children not to be wasteful with food, but their names are also children who like snacks; besides, I also don't really understand what is meant by best before and expired dates, so because I am afraid so I just throw away the food (Participant 2).

I do not understand that (best before and expired date), so let us leave it. Also, let the children enjoy snacks (Participant 24).

I have received training related to compost; I also understand how to use it. I am only training, there is no individual training, and I have to buy liquid, so that I decided to throw (Participant 23). 
Knowledge influences certain attitudes and behaviours when consumers decide to buy a product [13]. Knowledge of certain foods reduces the risk of useless food purchases and directly influences purchasing decisions [14]. According to Jarjusay (2017), regarding variations in date labelling terms, many do not understand it. That is due to the lack of information received by consumers [15]. Socialization regarding the role of packaging labels is very rare. This results in not all consumers knowing the difference and when the product can be consumed or not. Thus the food is immediately thrown away without thinking again.

I like to buy what my children and husband like, so it's useless if I cook them they don't like it. Just being happy (Participant 2).

I am a lot of kids, MBA, sometimes they like snacks, so it's not really a necessity, but the important thing is they like it (Participant 12).

There is a desire for the parent with affection and to buy more food than is necessary and to keep a large supply of food at home for the special person [16]. However, there are still participants who buy food products based on what they like, not what is needed. However, all participants are still trying to motivate themselves and work with their families to reduce food waste produced. Several psychographic factors (i.e. attitudes, interests or lifestyles) possessed by individual consumers have been shown to influence food waste [17].

I like to read, especially my husband is lecturing so sometimes he likes to tell stories about various things. Besides that, I also have a business, so I have to be diligent in reading about food (Participant 9).

In our waste bank, there are 32 items that can be sold, so yes, we will definitely separate the packaging. Not bad for pocket money (Participant 15).

I have received training related to compost, I also understand how to use it, but what about because it is only training, there is no individual training, and I have to buy liquid, so I decided to throw (Participant 23).

Differences in perceptions of how people make judgments about edible food are ultimately related to feelings of dislike and perceived lack of quality. [18]. This individual tendency can be a barrier to avoiding food waste for some consumers or perhaps as a factor in leaving leftovers food. Therefore, the practices and skills that households have around food can encourage or prevent food waste. Generally, all participants separate food waste from its packaging. This is because all participants are active members of a Besari Waste Bank who are used to separating food waste from its packaging.

\section{Conclusion}

The average participant contributed $327 \mathrm{~g}$ a day per person of non-packaged food waste while $24 \mathrm{~g}$ a day per person of packaged food waste. The results of the study state that knowledge, attitudes, and practice were related in decisions in determining what types of food are appropriate for them and their families to consume and which foods should be discarded.

The author would like to contribute to the School of Environmental Science Indonesia University and 2019-2020 PUTI Grants from Indonesia University that had provided support and fund for the author's research and paper publication.

\section{References}


1. L. K. Ivert, I. Dukovska-Popovska, R. Kaipia, A. Fredriksson, H. C. Dreyer, M. I. Johansson, L. Chabada, C. M. Damgaard, N. Tuomikangas, Sales and operations planning: responding to the needs of industrial food producers, $\mathrm{J}$. Production Planning \& Control, 26, 280-295 (2015)

2. HLPE, Food losses and waste in the context of sustainable food systems, A report by the High Level Panel of Experts on Food Security and Nutrition of the Committee on World Food Security, (8), (2014)

3. Barilla Center, Food sustainable index food loss and food waste country ranking USA, (2019)

4. M. Hebrok, C. Boks, Household food waste: drivers and potential intervention points for design - an extensive review, Journal of Cleaner Production, 151, 380-392 (2017)

5. H. K. Koivupuro, H. Hartikainen, K. Silvennoinen, J. M. Katajajuuri, N. Heikintalo, A. Reinikainen, L. Jalkanen, Influence of socio-demographical, behavioural and attitudinal factors on the amount of avoidable food waste generated in finnish households, International Journal of Consumer Studies, 36, 183-191 (2012)

6. R. O. Morawicki, D. J. D. González, Food sustainability in the context of human behavior, Yale Journal of Biology and Medicine, 91, 191-196 (2018)

7. K. G. Grunert, J. M. Wills, L. Fernández-Celemín, Nutrition knowledge, and use and understanding of nutrition information on food labels among consumers in the UK, Journal Appatite, 55, 177-189 (2010)

8. H. Williams, A. Lindström, J. Trischler, F. Wikström, Z. Rowe, Avoiding food becoming waste in households - the role of packaging in consumers' practices across different food categories, Journal of Cleaner Production, 265, 121-775 (2020)

9. Y. Rochwulaningsih, Dynamics of the Environmental Movement and Global Environmental Governance, J. Sejarah Citra Lekha, 2, 151-160 (2017)

10. Ministry of Environment and Forestry Indonesia, Food waste report 20172018, (2018)

11. UNEP, Prevention and reduction of food and drink waste in businesses and households - guidance for governments, local authorities, businesses and other organisations, (2014)

12. L. Ibanez, A. Stenger, Environment and food safety in agricul ture: are labels efficient?, Australian Economic Papers, 39, 452-464 (2004)

13. V. Stefan, E. V. Herpen, A. A. Tudoran, L. Lähteenmäki, Avoiding food waste by Romanian consumers: The importance of planning and shopping routines, Food Qual Prefer., 28, 375-38 (2013)

14. M. McCarthy, M. Brennan, A. L. Kelly, C. Ritson, M. de Boer, N. Thompson, Who is at risk and what do they know? Segmenting a population on their food safety knowledge, Food Qualityand Preference, 18, 205-217 (2007)

15. F. Jarjusay, Consumers' awareness and knowledge about food waste in selangor, malaysia, International Journal of Business and Economic Affairs, 2, 91-97 (2017) 
16. G. Porpino, J. Parente, B. Wansink, Food waste paradox: antecedents of food disposal in low income households, International Journal of Consumer Studies, 39, 619-629 (2015)

17. J. Aschemann-Witzel, A. Giménez, G. Ares, Suboptimal food, careless store? consumer's associations with stores selling foods with imperfections to counter food waste in the context of an emerging retail market, Journal of Cleaner Production, 262, 121-252 (2020)

18. C. Hartmann, M. Siegrist, Development and validation of the food disgust scale, Food Quality and Preference, 63, 38-50 (2018) 